\title{
"Ningún lugar sagrado" de Rodrigo Rey Rosa: una ficción paranoica desde la diáspora centroamericana
}

\author{
Marileen La Haije ${ }^{1}$ (D)
}

Accepted: 27 November 2020 / Published online: 22 December 2020

(c) The Author(s) 2020

\begin{abstract}
This paper analyzes "Ningún lugar sagrado" (1998) by the Guatemalan writer Rodrigo Rey Rosa as a 'ficción paranoica' ("La ficción paranoica", Clarín, 10 de octubre de 1991; Blanco nocturno, Anagrama, Barcelona, 2010). I will explain that Rey Rosa's short story does not include univocal clues to identify the protagonist as an unreliable narrator whose overinterpretations give rise to a misrepresentation of the facts. According to my reading of "Ningún lugar sagrado", the paranoiac features of the main character contribute to the ambiguity of the text that, in fact, never explicitly confirms or discredits his persecutory ideas. Following this line of argument, I suggest that Rey Rosa's short story narrates an "imaginario de amenaza" ("La ficción paranoica", Clarín, 10 de octubre de 1991) that, alluding to the climate of repression, intrigues and complicities in postwar Guatemala, generates paranoia -including that of the reader. "Ningún lugar sagrado" points to a more general tendency in recent Central American literature that, from the realm of fiction, highlights the widespread nature of paranoia in the region. Unlike social discourses that discuss the topic, these literary texts make use of narrative techniques that do not necessarily respond to a referential notion of truth (including hyperboles, digressions, irony and narrative ambiguity), when constructing the voice of a paranoiac character. According to my perspective, such narrative techniques lend themselves especially to capturing the alienating dimensions of violence in Central America where paranoia, rather than being a question of truth or exaggeration, constitutes a survival strategy.
\end{abstract}

Keywords "Ningún lugar sagrado" · Rodrigo Rey Rosa · Paranoia · 'Ficción paranoica' · Unreliable narration

Marileen La Haije

m.lahaije@let.ru.nl

1 Romaanse Talen en Culturen, Faculty of Arts, Radboud University, Nijmegen, The Netherlands 


\section{Repensar la paranoia desde la ficción centroamericana}

En "Better not say too much" (2015), el escritor guatemalteco Eduardo Halfon describe las cosas cotidianas que hacen los guatemaltecos en lo que él llama su "normal, everyday psychotic state": "frequently altering my route to work, avoiding dead-end streets and dark alleys, never driving alone at night (I have a friend who even bought a mannequin, and would sit it next to her in the passenger's seat and pretend they were having a conversation as she drove)". Compartiendo su visión, Horacio Castellanos Moya sostiene en una entrevista reciente a propósito de la publicación de su novela Moronga (2018) que "en Centroamérica quien no se convierte en paranoico, muere. Y quien es paranoico también puede morir, porque la violencia es demasiada, pero los paranoicos seguramente tienen más oportunidades de sobrevivencia que quien no es paranoico" (Wallace 2018). Según el escritor hondureñosalvadoreño, en países centroamericanos como El Salvador, Guatemala y Honduras, la paranoia se ha convertido en "parte de la cultura nacional, parte natural", "una forma de ser, una forma de sobrevivir" (Wallace 2018). Dice Castellanos Moya que "los personajes que vienen de esos lugares no pueden sino ser paranoicos" (Wallace 2018).

Me parecen sugerentes las observaciones de Eduardo Halfon y Horacio Castellanos Moya que complejizan una interpretación de la paranoia en términos patológicos, identificándola como un estado psicótico 'normal' o forma de ser y sobrevivir en las sociedades centroamericanas actuales. Lejos de calificar al personaje paranoico como una excepción patológica, los autores dan cuenta del contexto sociopolítico de violencia generalizada en Centroamérica que dispara la paranoia. De esta manera, interrogan la asociación entre la paranoia y la exageración; asociación que se reproduce en los discursos psicológicos. Por ejemplo, los autores de Paranoia. The 21st-Century Fear (2008) describen la paranoia como la "exaggerated or unrealistic idea that others wish to harm us" (Freeman and Freeman 2009) y el Diagnostic and Statistical Manual of Mental Disorders (DSM) habla de una "excessive suspiciousness and hostility" (American Psychiatric Association 2013). Halfon y Castellanos Moya reconocen el hecho de que las conductas paranoicas de los centroamericanos no son exageraciones o reacciones irrealistas, sino que responden a una estrategia de sobrevivencia.

$\mathrm{El}$ argumento de los autores centroamericanos concuerda con las ideas de Ignacio Martín-Baró acerca de la "anormal normalidad" que, según el psicólogo social, caracteriza situaciones de violencia generalizada en el Istmo (1990: 35). En tales casos, dice él, puede ocurrir que un "trastorno psíquico" constituya una "reacción normal frente a una situación anormal" (35). Habla en este contexto de su experiencia con grupos de campesinos desplazados por la guerra en El Salvador que, a primera vista, parecían mostrar "trazas de delirio paranoide":

Estaban constantemente alertas, multiplicaban las instancias de vigilancia, no se fiaban de nadie desconocido, sospechaban de todos cuantos se acercaran a ellos, escrutaban los gestos y las palabras en busca de posibles peligros. Y, sin embargo, conocidas las circunstancias por las que habían pasado, los peligros reales que aún les acechaban, así como su indefensión e impotencia 
para enfrentar cualquier tipo de ataque, uno llegaba pronto a comprender que su comportamiento de hiperdesconfianza y alerta no constituía un delirio persecutorio fruto de sus ansiedades, sino el planteamiento más realista posible dada su situación vital [...]. Se trataba, sin lugar a dudas, de la reacción más normal que podía esperarse ante las circunstancias que les tocaba enfrentar (35).

Vemos entonces que Martín-Baró despatologiza las conductas lindantes con la paranoia de los campesinos salvadoreños afectados por la represión militar. Lejos de descalificar tales conductas como acciones desmedidas, producto del delirio, el psicólogo social da cuenta del clima represivo de la guerra en El Salvador donde la desconfianza profunda y la hipervigilancia serían reacciones 'normales' y realistas.

Son varios los textos literarios centroamericanos que, poniendo en cuestión la idea de la paranoia como trastorno psíquico, interrogan la asociación entre la paranoia y la exageración. Desde el ámbito de la ficción, estas narrativas dan cuenta de la paranoia generalizada en tanto horizonte de vida en Centroamérica. A diferencia de los discursos sociales que abordan este tema, los textos de ficción hacen uso de recursos narrativos que no necesariamente responden a una noción referencial de la verdad (incluyendo la hipérbole, la digresión, la ironía y la ambigüedad narrativa), a la hora de acercarse a la voz del personaje paranoico. Desde mi punto de vista, este tipo de recursos se prestan especialmente para captar la dimensión desbordante y enajenante del fenómeno de la violencia en Centroamérica donde la paranoia, más que una cuestión de verdad o exageración, constituye una estrategia de sobrevivencia.

Los relatos de ficción de Horacio Castellanos Moya, poblados de personajes paranoicos en situaciones de guerra y posguerra, presentan un caso ilustrativo al respecto. Por ejemplo, su novela Insensatez (2004) no descalifica, sin más, las ideas de persecución y conspiración del protagonista como producto del delirio. También destaca el contexto represivo de la posguerra guatemalteca que dispara la paranoia. Algo similar ocurre en el cuento del escritor guatemalteco Rodrigo Rey Rosa, "Ningún lugar sagrado" (1998), que voy a estudiar con más detalle en este trabajo.

El protagonista y narrador del cuento, cuyo nombre no conocemos, es un cineasta guatemalteco que se encuentra exiliado en Nueva York. Recibe una visita inesperada de su hermana, Antonia, quien se ha visto obligada a salir de Guatemala a causa de las amenazas que ha recibido. Antonia forma parte de un grupo de activistas políticos que exigen la investigación de varios crímenes cometidos en la Guatemala de fines de los años noventa -época en la que tiene lugar la historia. El cuento alude en este contexto al asesinato en 1998 del obispo guatemalteco Juan Gerardi, quien dirigió el Proyecto Interdiocesano de Recuperación de la Memoria Histórica (REMHI). A partir de la visita de su hermana, el protagonista de "Ningún lugar sagrado" empieza a interpretar los hechos que ocurren en Nueva York en clave de desaparición y persecución políticas; interpretaciones de las que no siempre se aclara si son producto de la imaginación o no.

De acuerdo con mi lectura, el cuento de Rey Rosa complejiza una interpretación del relato del personaje paranoico en términos de narración no fidedigna. Para explicar este argumento, me parece relevante hacer referencia a las ideas de Lars 
Bernaerts quien, en De retoriek van waanzin (2011), califica al personaje paranoico como narrador no fidedigno. Según Bernaerts, este tipo de personajes tienden a desarrollar interpretaciones 'desmedidas' que, alimentadas por sus ideas delirantes, dan lugar a una tergiversación de los hechos, lo que él llama "overreading" (209). Constata que, para poder determinar un caso de "overreading" y, con él, un caso de narración no fidedigna, es preciso que se incluya una perspectiva correctiva en el texto (97): una instancia narrativa que cuestione la versión de los hechos que nos presenta el personaje paranoico. Asimismo, las referencias explícitas a la paranoia en el tex to literario funcionarían como un marco de referencia para interpretar lo que él llama las 'rarezas' del discurso del narrador (212).

A la hora de interpretar el relato del personaje paranoico como un caso de "overreading", se reproduce la asociación entre la paranoia y la exageración. "Ningún lugar sagrado" problematiza esta asociación. En efecto, varios fragmentos del cuento carecen de una instancia narrativa u otras claves que permitan calificar al personaje paranoico como un narrador no fidedigno. Reconociendo su carácter ambiguo, creo que este texto no pretende desacreditar (ni convalidar) las ideas persecutorias del protagonista como interpretaciones desmedidas que dan lugar a una tergiversación de los hechos. Más bien, construye un imaginario de amenaza que dispara la paranoia -incluyendo la del lector.

En relación con esto, me parecen pertinentes las observaciones de Ricardo Piglia acerca de la ficción paranoica. Según Piglia, "la literatura se ha hecho cargo cada vez más del desarrollo del imaginario de la amenaza de la vida cotidiana puesta en peligro" (1991). Esto daría lugar a lo que él ha definido como un nuevo género policial, la ficción paranoica:

Todos son sospechosos, todos se sienten perseguidos. El criminal ya no es un individuo, sino una gavilla que tiene el poder absoluto. Nadie comprende lo que está pasando; las pistas y los testimonios son contradictorios y mantienen las sospechas en el aire, como si cambiaran con cada interpretación (2010: 284).

José Luis de Diego establece un vínculo entre la noción de la ficción paranoica y la idea del Estado 'paranoico' que, aludiendo a la última dictadura argentina, no admite voces críticas. En tales contextos de represión, dice De Diego, el sujeto paranoico dejaría de ser un "individuo psicótico" para convertirse en lo que él llama "un resto, una marginalidad lúcida, una ética no contaminada, una verdad inconmovible" (2014: 10, cursivas en el original). Me parece sugerente este argumento que reconoce la necesidad de despatologizar al sujeto paranoico en situaciones de violencia política -patologizando, en cambio, el Estado totalitario. Además, De Diego complejiza el perfil del personaje paranoico como narrador no fidedigno al constatar que este encarna una "marginalidad lúdica", una "verdad inconmovible".

Desde mi punto de vista, es acertado el uso de la noción de la ficción paranoica en el análisis de "Ningún lugar sagrado" y otras narrativas centroamericanas que, aludiendo al clima represivo de la guerra y posguerra en Centroamérica, construyen un imaginario de amenaza donde las sospechas se mantienen en el aire. Antes de explorar dicho imaginario en el cuento de Rey Rosa, estudiaré primero el contexto 
discursivo dentro del cual se narran las ideas persecutorias del personaje principal: las sesiones psicoanalíticas con la doctora Rivers, psicóloga estadounidense.

\section{Movimientos digresivos hacia recuerdos traumáticos}

"No quiero irme por las ramas" (Rey Rosa 1998: 68), dice el protagonista de "Ningún lugar sagrado" durante la primera sesión con la doctora Rivers. Se refiere acá al carácter digresivo de su relato en el que, habiendo hecho un comentario sobre la alfombra marroquí que se encuentra en el despacho de la psicóloga, empieza a hablar sobre su estadía en Fez que le parece un "país encantador", añadiendo que "aunque a veces es difícil, usted sabe, el islam", para luego hablar de los judíos marroquíes que regresaron de Israel a Marruecos a causa de la discriminación ("porque tienen rasgos, costumbres africanas"), concluyendo que se trata de un caso de racismo (68). Al rectificar su discurso digresivo, diciendo que no quiere irse por las ramas, el personaje reproduce la común percepción de la digresión como error. Como sostiene María Paz Oliver en El arte de irse por las ramas (2016), la digresión suele ser entendida como un "acto fallido" (13), un "error lógico" (10) o "error de continuidad y coherencia" (1).

Más adelante, el discurso del narrador de "Ningún lugar sagrado" sigue el mismo movimiento digresivo a partir del cual llega a reflexionar sobre su sueño juvenil con ser santo: "A veces me parece que la santidad, por absurdo que suene, es la única salida. El desprendimiento, la ascética. Huir del mundo. Pero tal vez es imposible huir, y por eso estoy aquí" (68). Me parece interesante esta reflexión que alude al estatuto del protagonista como exiliado político. Más adelante, en efecto, define el hecho de que se fue de Guatemala en términos de "huida" (86). Dándose cuenta de que no es posible desprenderse del pasado, el narrador decide acercarse, desde el exilio, a la memoria de la represión en Guatemala de la que huyó hace años. El título del cuento apunta a esta imposibilidad de escapar, puesto que no hay ningún lugar sagrado o intocable. ${ }^{1}$

A continuación, la psicóloga le invita a sentarse "en el diván” (68) -señal de que se inicia la sesión psicoanalítica- y propone utilizar el método de la asociación libre. A partir de esta propuesta, el cuento introduce una noción de la digresión que, en vez de señalar su carácter errático, destaca lo que María Paz Oliver ha llamado su "potencial creativo" como "expresión de un sistema de asociación de ideas" (2016: 31). Oliver retoma, en este contexto, las ideas de Pierre Bayard quien, a propósito de su análisis de la obra narrativa de Marcel Proust, introduce una aproximación psicoanalítica a la digresión. De acuerdo con la perspectiva de Bayard, la digresión sería la "encargada de justificar la serie de mutaciones y avances en la narración a través de [...] enlaces inconscientes" (Oliver 2016: 31). En su interpretación de los mecanismos de asociación de ideas, dice Oliver, el literato y psicoanalista francés "rescata de la teoría de Freud, por un lado, el rol del inconsciente en el uso de la digresión para unir dos ideas y, por otro, cómo en esa conexión siempre hay un movimiento de

\footnotetext{
${ }^{1}$ El título también tiene un evidente significado sexual relacionado con la entrega del cuerpo que se describe en la escena final del cuento.
} 
resistencia frente a la censura" (31). Se refiere acá a la censura de los contenidos del inconsciente.

En relación con esto, me parece sugerente la nota de Rodrigo Rey Rosa al inicio de la colección de cuentos, titulada Ningún lugar sagrado (1998), que incluye la noción de censura. Dice el autor guatemalteco que "Ningún lugar sagrado" es el resultado de un "ejercicio de escritura semiautomática donde se combinan circunstancias imaginarias y elementos más o menos conformes a la historia reciente de Guatemala, sin censura alguna y con absoluta irresponsabilidad" (7). Es significativo el uso de la expresión "sin censura alguna" en esta nota que puede interpretarse de distintas maneras.

Por un lado, podríamos interpretar esta expresión en relación con los contextos de violencia política centroamericanos donde la (auto)censura ha sido, y sigue siendo, práctica común. ${ }^{2}$ De acuerdo con esta perspectiva, el contexto del exilio en el que Rey Rosa escribió el cuento -Cali, Colombia (7)- le permitiría hablar sobre la historia reciente de Guatemala sin tener que preocuparse por posibles represalias que, en la posguerra guatemalteca, todavía están a la orden del día. Es relevante, al respecto, la fecha en la que el autor escribió el texto: mayo del año 1998, un mes después del asesinato del obispo guatemalteco Juan Gerardi, director del proyecto REMHI. En efecto, el protagonista de "Ningún lugar sagrado" se refiere a este hecho histórico en una de las sesiones con la doctora Rivers para ilustrar la idea de que "se ha firmado la paz, pero no existen garantías" (73).

Por otro lado, podríamos interpretar la expresión "sin censura alguna" en relación con el fundamento teórico de la asociación libre. Según Sigmund Freud, a partir de la asociación libre se pondrían al descubierto las resistencias frente a la censura de los contenidos del inconsciente. El análisis de dichas resistencias sería clave para la curación del paciente. De acuerdo con estas ideas, creo que "Ningún lugar sagrado" recurre a la digresión en tanto recurso estético para reproducir la lógica de la asociación libre.

Las digresiones que se incluyen en el cuento de Rey Rosa son proliferativas, en el sentido de que crean una trama que "prolifera hacia una serie de centros transitorios" (Oliver 2016: 25). Dice María Paz Oliver que el discurso digresivo, en este caso, "dispone de manera episódica núcleos que desvían la dirección inicial de la trama" (25). En este tipo de discursos, suele introducirse un "contrapunto en cada desvío" (Oliver 2016: 25), a partir del cual el núcleo que transitoriamente desvía la dirección inicial de la trama deja de ser un punto de referencia. En "Ningún lugar sagrado", las preguntas de Rivers (que sólo se deducen de las réplicas del protagonista) funcionan a menudo como contrapunto de los desvíos del narrador. Con preguntas específicas, la psicóloga redirige las asociaciones libres de su paciente hacia temas como la

\footnotetext{
${ }^{2}$ En su ensayo antes citado, Eduardo Halfon habla sobre la cultura del silencio en Guatemala que, dice él, sigue vigente hasta el día de hoy, afectando también a la profesión del escritor: "How can a novelist or a poet say anything truthful about their own people, about the social inequality, about the intolerable levels of racism and poverty, if their very life hangs on the words of those novels or poems? They can't. [...] The novelist can't allow him or herself to be truthful. And the poet simply ceases to be a poet. Unless, as recent history shows, and as I was told by a Salvadoran writer [Horacio Castellanos Moya], they leave" (2015).
} 
relación con sus padres (68) y su hermana (72), los recuerdos de la infancia (69) y las pesadillas (75), con el fin de sacar a la luz los nudos traumáticos de su pasado.

Es ilustrativo el pasaje del cuento que pone de manifiesto la manera en que Rivers, desde una perspectiva psicoanalítica, subordina los distintos núcleos narrativos que el protagonista ha ido explorando a partir de la asociación libre en una trama coherente y totalizadora: el complejo de Edipo. Reproduciré acá algunas partes del fragmento que son relevantes para este análisis:

¿Culpa? ¿Por qué me iba a sentir culpable? Ya, desde luego. Pero yo nunca lo vi de esa manera. Por favor, explíquemelo. Ya. Ajá. Maravilloso. Usted cree de verdad que en el fondo yo me alegré con [la muerte de mi padre]. ¿Por la manera como se lo conté? Edipo, ya veo. [...] ¡Ah! Por eso siento culpa. [...] Vaya, qué complicado. No, es interesante. Así que estoy «enamorado» de mi hermana. Me divierte ese gesto, tan norteamericano, de dibujar las comillas con los dedos, como acaba de hacer. Estoy o estuve enamorado entre comillas, primero de mi madre y luego de mi hermana. Una mejora, ¿no? [...] Interesantísimo, doctora. Genial. Y todo eso por obra del subconsciente. ¿Mi relación con el poder? Bueno, la autoridad. Ya, doctora, pero si el poder, el poder político en este caso, la autoridad en Guatemala, es una representación del Padre con mayúscula, ¡desde luego que hay que matar al padre! Sí, yo mismo se lo he dicho, creo que más de una vez, me siento un poco cómplice. Ah, le he dejado el papel de mata-padres a mi hermana. Comprendo. No, sólo un poco tirado por los pelos. Razonando así, yo a usted la situaría del lado del poder. Rivers, River's, Del Río. Es el nombre de uno de esos generales de los que le hablé. El golpista. Un fanático, un loco. Demasiado cómodo. Como para libro, ¿no? Dejémoslo ahí. Claro que voy a reflexionar (82).

Son varios los elementos que me interesa destacar de este fragmento. Primero, vemos que el protagonista adopta una perspectiva incrédula con respecto a la interpretación psicoanalítica de Rivers. Expresiones como "vaya qué complicado" y "un poco tirado por los pelos" apuntan al carácter rebuscado de sus ideas acerca del complejo de Edipo. Asimismo, el personaje se burla de esta noción psicoanalítica, diciendo que el hecho de que primero estuvo enamorado (entre comillas) de su madre y luego de su hermana presenta "una mejora".

Además, este y otros fragmentos del cuento ponen de relieve el enfoque psicoanalítico del trauma cuyo eje es el funcionamiento psíquico individual. En relación con esto, me parece relevante hacer referencia a las ideas de Stef Craps quien, en Postcolonial Witnessing (2013), introduce una perspectiva crítica acerca de los enfoques individualistas del trauma:

By narrowly focusing on the level of the individual psyche, one tends to leave unquestioned the conditions that enabled the traumatic abuse, such as political oppression, racism, or economic domination. Problems that are essentially political, social, or economic are medicalized, and the people affected by them are pathologized as victims without agency, sufferers from an illness that can be cured through psychological counselling (28). 
Al definir el trauma exclusivamente en términos psicológicos, este tipo de enfoques individualistas desatenderían sus raíces sociopolíticas, patologizando, a la vez, al sujeto traumatizado como víctima desprovista de agencia. La perspectiva psicoanalítica de Rivers en "Ningún lugar sagrado" se caracteriza por una similar desatención con respecto al contexto de violencia política en Guatemala. La psicóloga estadounidense individualiza los traumas de su paciente, centrándose en los motivos familiares que forman parte de la noción del complejo de Edipo (odio o rivalidad hacia la figura del padre, atracción hacia la figura de la madre). Así, pasa por alto la raíz sociopolítica de los episodios traumáticos que le cuenta el personaje: el asesinato del padre o el secuestro de la madre, por ejemplo.

Vemos, sin embargo, que la asociación libre que hace el protagonista a partir del nombre de la psicóloga redirige la atención hacia la realidad violenta en Guatemala: "Razonando así, yo a usted la situaría del lado del poder. Rivers, River's, Del Río. Es el nombre de uno de esos generales de los que le hablé. El golpista. Un fanático, un loco" (82). El texto incluye acá una clara referencia al dictador guatemalteco Efraín Ríos Montt (1982-1983). ${ }^{3}$ El uso del condicional ("situaría") en este fragmento señala el carácter irónico de la observación del protagonista quien se burla del método psicoanalítico de la asociación libre. Llevando a un extremo este método, el personaje describe una situación hipotética absurda donde Rivers estaría en el lugar de Ríos Montt.

Al mismo tiempo, la asociación entre el nombre de la psicóloga estadounidense y el nombre del dictador guatemalteco apunta a lo que María Paz Oliver ha llamado el "filo político" de la digresión (2016: 7). Este se dirige, en el cuento de Rey Rosa, a la complicidad de los Estados Unidos en la guerra en Guatemala. Efectivamente, en una sesión anterior el protagonista calificó la política exterior de los Estados Unidos como "asquerosa" (71), refiriéndose al contexto guatemalteco: "Ellos, ustedes, han financiado, planeado, supervisado, las famosas matanzas de indios, de estudiantes, de izquierdistas en los últimos treinta años" (71). ${ }^{4}$ Añade que "no sólo han dado las armas, han fundado las escuelas donde han sido formados los dictadores, los especialistas, los asesinos y torturadores que han hecho todas esas barbaridades" (71). El narrador se refiere acá a la notoria Escuela de las Américas donde, de hecho, Efraín Ríos Montt fue entrenado.

\section{Las sospechas se mantienen en el aire}

A partir de la visita inesperada de Antonia, su hermana, el protagonista empieza a desarrollar una serie de interpretaciones de índole paranoica que, durante las sesiones con la doctora Rivers, interrumpen sus asociaciones libres. En relación

\footnotetext{
${ }^{3}$ Vemos que el protagonista de "Ningún lugar sagrado" califica a Ríos Montt como un perpetrador loco; imagen que, en efecto, es común en el contexto de la posguerra en Guatemala.

${ }^{4}$ Luego, el protagonista matiza la noción de "ustedes", diciendo que "claro que no quiero decir que todos sean igualmente culpables. La prensa los tiene desinformados, es cierto, pero también es cierto que a muy poca gente aquí le interesa lo que ocurre verdaderamente allá" (71).
} 
con esto, me parece relevante considerar las ideas de Samuel Frederick quien, en su análisis de la novela Verstörung (1967) de Thomas Bernhard, sugiere un nexo entre la digresión y el delirio: "Delirium, after all, like digression means 'to deviate from the straight path' (de- [away from] + lira [furrow])" (2012: 106). Según Frederick, la novela de Bernhard "enacts an allegory of digressivity as the rule of law 'gone mad,' such that the reigning logic of plot over narrative shifts away (as per the etymology of ver-rückt, mad) from its central position" (106). De esta manera, dice él, la novela tematiza a la vez que actúa (utiliza la palabra "performing") un "mad discourse" (106).

Para el caso específico de la paranoia, no creo que valga este nexo con la digresión. A diferencia de la "fuerza centrífuga" del discurso digresivo que esquiva un núcleo o centro narrativo (Oliver 2016: 15-16), el discurso del paranoico se caracteriza más bien por una fuerza centrípeta cuyo núcleo es una trama totalizadora (de conspiración o persecución). Mientras que el discurso digresivo suele ser leído como un "error de continuidad y coherencia" (Oliver 2016: 1), el discurso del paranoico presenta una trama coherente y bien urdida. Este no se va por las ramas. Un similar contraste entre el movimiento centrífugo del discurso digresivo y el movimiento centrípeto del discurso del paranoico se observa en el relato del protagonista de "Ningún lugar sagrado". A diferencia de los fragmentos en los que, a partir de la asociación libre, el personaje va explorando distintos núcleos narrativos, su discurso no se va por las ramas durante los momentos de paranoia.

Esta interrupción de la asociación libre se destaca, por ejemplo, en el fragmento donde el protagonista le comenta a la doctora que se está "volviendo loco" por el hecho de que Antonia "ha desaparecido" (78). Describe el ataque de pánico que tuvo la noche anterior, al haberse dado cuenta de que su hermana no había llegado a casa: "Me imaginaba lo peor. Que habían mandado unos matones detrás de ella. Delirante. Hasta de usted dudé. Que podía ser una confidente" (79). Vemos que el protagonista descalifica, desde una perspectiva retrospectiva, su interpretación de los hechos en clave de desaparición política como "delirante". Incluso, considera también la posibilidad de que su hermana "simplemente se haya ido de juerga, no sería la primera vez" (78) -interpretación que luego resulta ser cierta.

Cabe señalar que su interpretación de los sucesos en clave de desaparición política no parece tan descabellada, considerando el hecho de que su hermana y otros activistas guatemaltecos publicaron una lista de nombres de los posibles sospechosos del asesinato del obispo guatemalteco Juan Gerardi: "una temible colección, las fuerzas vivas y más o menos ocultas del país, que todos saben que son capaces de cualquier cosa" (74). El protagonista añade que "las amenazas no han faltado" (74), lo cual resulta ser el motivo por el que su hermana ha ido a visitarle en Nueva York. Le explica a su psicóloga que "por eso me preocupo, doctora. Claro que la podrían matar por algo así. Por menos. A ella o alguien cercano” (74). De acuerdo con mi lectura de "Ningún lugar sagrado", la paranoia se presenta en este y otros fragmentos del cuento como una reacción 'normal' o 'realista' ante circunstancias de represión política que persisten en el presente de la narración.

En relación con esto, es significativo el pasaje donde el narrador, respondiéndole a la psicóloga, dice lo siguiente: “¿Miedo? Estamos acostumbrados al miedo. Normal, tal vez no. ¿Adictos? Claro que no me gusta sentir miedo" (80). La respuesta 
del personaje recuerda las observaciones de Horacio Castellanos Moya acerca de la paranoia como "parte natural" en las sociedades centroamericanas actuales, una forma de ser y sobrevivir en una región donde la violencia es "demasiada" (Wallace 2018). Retratando a un personaje que sigue siendo paranoico fuera del Istmo, "Ningún lugar sagrado" no sólo pone de manifiesto la persistencia de los traumas de la guerra en Guatemala. También apunta a la imposibilidad de desprenderse psíquicamente de la paranoia generalizada que constituye el horizonte de vida en Centroamérica.

Siguiendo este argumento, creo que el cuento de Rey Rosa complejiza una interpretación del relato del personaje paranoico en términos de narración no fidedigna. En efecto, a diferencia del fragmento antes mencionado donde, como vimos, el narrador descalifica sus ideas acerca de la desaparición de Antonia como producto del delirio, los pasajes que se incluyen más adelante carecen de claves unívocas que desacrediten o confirmen su relato de los hechos.

Es ilustrativo el fragmento en el que el protagonista llega al despacho de la doctora Rivers, pálido y sudando, creyendo ser perseguido por un oreja guatemalteco. A partir de ahí, empieza a hablar de lo que les pasó a él y su hermana la noche anterior. Según cuenta, un oreja guatemalteco -“colega” del que le persiguió (85)- entró en su casa y quedó atrapado en la ventanilla del armario del baño. El protagonista logró hacerle perder el sentido con unos martillazos y encerrarle en el armario, después de lo cual llamó a la policía. "Bien hecho, hombre" (88), le habría dicho uno de los agentes. De los comentarios del narrador podemos deducir que la psicóloga no está convencida de la veracidad de las ideas persecutorias de su paciente: "claro que cuesta ver desde aquí, son nueve pisos, pero estoy seguro de que es él" (85), o más adelante, "mire, sigue allá. El tipo ese. Venga a ver, claro que es el mismo. Pero doctora, ¿por qué no me cree?” (89). Con el fin de convencerle del carácter verídico de sus ideas, el protagonista le dice lo siguiente: "ya sé que cree que deliro, y es posible que delire, pero lo de ese tipo no es paranoia, doctora. Ya lo verá" (89). Me parece llamativo que el personaje afirme que sus posibles delirios no son producto de la paranoia; argumento que se basa en la noción de la paranoia en tanto exageración. Al desvincular sus ideas persecutorias de la paranoia, pretende rebatir la idea de que está exagerando o tergiversando los hechos.

Al mismo tiempo, el cuento de Rey Rosa sugiere la posibilidad de que no sean ciertas las ideas persecutorias del personaje al incluir la palabra paranoia. De acuerdo con las observaciones de Lars Bernaerts, este tipo de referencias explícitas podrían funcionar como un marco de referencia para interpretar las 'rarezas' del relato del narrador (2011: 212). Semejante interpretación correspondería a la perspectiva de Rivers quien, como vimos, pone en cuestión el carácter verídico de las ideas persecutorias del personaje. En otras palabras, tomaríamos, como lectores, la posición de la psicóloga estadounidense quien evalúa con distancia crítica las sospechas de su paciente.

El análisis de "Ningún lugar sagrado" que propongo en este trabajo va por otro camino. Desde mi punto de vista, la observación del narrador acerca de la paranoia contribuye a la ambigüedad del cuento que, de hecho, nunca confirma o desacredita explícitamente sus ideas persecutorias. En relación con esto, me parece relevante hacer referencia al argumento de Beatriz Cortez quien da por hecho que 
el protagonista de "Ningún lugar sagrado" está siendo perseguido. Desde su punto de vista, el cuento de Rey Rosa no deja lugar a duda acerca de la veracidad de las sospechas del personaje quien, dice ella, "permanece relativamente calmado" a pesar de la "certeza de que está siendo perseguido por las calles de Nueva York" (2010: 195). Según Cortez, "Ningún lugar sagrado" da cuenta de la "situación de inseguridad y de riesgo" que afecta a gran parte de los centroamericanos, incluso los que viven fuera de la región (193). Compartiendo esta visión, creo que el cuento de Rey Rosa muestra la articulación entre Centroamérica y la diáspora centroamericana, introduciendo a un personaje que, estando fuera del Istmo, sigue siendo afectado psicológicamente por la realidad violenta en su país natal. Desde una perspectiva distinta a la de Cortez, mi lectura de "Ningún lugar sagrado" intenta dar cuenta del carácter ambiguo del relato del narrador.

De acuerdo con esta perspectiva, me parece que el texto va construyendo un imaginario de amenaza que, aludiendo al clima de represión, intrigas y complicidades que caracterizan los primeros años de la posguerra guatemalteca, da lugar a distintas interpretaciones por parte del lector -algunas de las cuales lindan con la paranoia. Una de las sospechas que creo que dispara la lectura del cuento tiene que ver con la idea de que la doctora Rivers podría ser una informante de los servicios de inteligencia estadounidenses. Recordemos las palabras del narrador quien, hablando de su estado alterado a causa de la desaparición de Antonia, dice que "hasta de usted dudé. Que podía ser una confidente" (79). Vimos que el personaje descalifica retrospectivamente esta idea como delirante. No obstante, el cuento de Rey Rosa no excluye la posibilidad de que sus sospechas acerca de la psicóloga sean ciertas. A continuación, exploraré las implicaciones de esta idea.

\section{El trauma desde el psicoanálisis, el trauma desde la paranoia}

Teniendo en mente la posibilidad de que Rivers sea una espía, algunas de sus intervenciones resultan tener un aire sospechoso. Por ejemplo, en una de las conversaciones por teléfono, la psicóloga le hace una serie de preguntas al protagonista acerca de los amigos latinoamericanos de Antonia que se encuentran exiliados en los Estados Unidos: sobre sus profesiones ("uno es arqueólogo forense. Trabajó en ese informe del arzobispado que dirigía el cura que asesinaron. Desde luego, se asustó, y se vino para acá. ¿Los otros? Otro es salvadoreño, locutor de radio. Hay otro, cubano, que es músico. Nueva trova. Un poco de protesta, sî”), si están metidos en política ("claro que es posible que estén metidos en política"), y si están metidos en la política estadounidense ("no lo creo, pero puedo preguntar") (79-80).

A propósito de su análisis de "Ningún lugar sagrado", Beatriz Cortez sugiere que este tipo de preguntas ponen de manifiesto la ignorancia de la psicóloga estadounidense con respecto a la realidad sociopolítica en Guatemala, diciendo que ella "no comparte las experiencias de estos exiliados" (293). Desde mi punto de vista, el cuento de Rey Rosa no excluye la posibilidad de que Rivers finja ser ignorante para, así, encubrir su propósito de sacarle información al narrador sobre los amigos latinoamericanos de Antonia quienes, al igual que ella, están involucrados en el activismo político. Siguiendo este argumento, las preguntas de la psicóloga podrían 
ser interpretadas como parte de un interrogatorio llevado a cabo bajo el pretexto del psicoanálisis.

En relación con esto, son pertinentes las ideas de Peter Brooks acerca del vínculo entre el psicoanálisis y el interrogatorio policial. En Troubling Confessions (2000), Brooks se centra en la interacción entre el analizante o paciente (el interrogado) y el analista (el interrogador):

What the analysand confesses most easily [...] is always an object of suspicion to the analyst, since the matter easily confessed is usually not what is causing the neurosis. Confessions by the analysand can serve many motives -shame, guilt, revenge, self-justification, self-abasement- but the deeper sources of shame and guilt are blocked from confession by repression [...]. Psychoanalytic work must normally be directed not so much to confession as to the resistance to confession, working to uncover what the analyst -somewhat in the manner of the interrogator- knows the analysand knows, but knows only unconsciously. "Truth" is to be sought in those places that have been marked by censorship. It is not the voluntary confession that interests the analyst, but the involuntary -that which can be coerced from the analysand in the course of analytic work (53).

Haciendo uso de palabras relacionadas con la resistencia a la confesión, la confesión involuntaria y la coerción, Brooks establece un nexo entre, por un lado, los métodos coercitivos a los que recurre el psicoanalista (la asociación libre, entre otros) para poner al descubierto los contenidos del inconsciente y, por el otro, los métodos coercitivos a los que recurre el interrogador (incluyendo la picana y otras técnicas de tortura física y psíquica) con el fin de sustraer datos del enemigo.

En "Ningún lugar sagrado", pareciera que Rivers recurre a los métodos coercitivos del psicoanálisis para conseguir esto último: sustraer datos del enemigo. ${ }^{5} \mathrm{De}$ acuerdo con esta perspectiva, ella utilizaría al protagonista como fuente de información sobre su hermana y otros activistas políticos que exigen la investigación de varios crímenes cometidos recientemente en Guatemala, como el asesinato del obispo Juan Gerardi. Es sugerente, al respecto, la observación que hace el protagonista en una de las primeras sesiones psicoanalíticas sobre el rol del FBI en la investigación de este crimen. Dice que los agentes del FBI que llegaron algunos días después del asesinato del obispo guatemalteco para "colaborar en la investigación" hasta ahora no han averiguado nada (73). Según nos cuenta él, las "malas lenguas dicen que llegaron sólo para borrar las huellas que los agentes guatemaltecos pudieron dejar intactas, con el riesgo de que algún investigador privado contratado por Minugua o por el arzobispado o alguna organización no gubernamental las encontrara" (73-4), añadiendo que "claro que todo el mundo sospecha que detrás

\footnotetext{
5 Siguiendo este argumento, se podría interpretar el hecho de que Rivers le invita al protagonista a su casa donde, después de haberle emborrachado, le lleva a la cama como otro método para sustraer datos del enemigo. En efecto, la seducción es una de las técnicas más probadas entre espías femeninas, siendo Mata Hari (1876-1917) un ejemplo paradigmático de tales métodos de espionaje (Bogle 2001: 105).
} 
de esto debe de haber algún personaje importante, a quien quizá los norteamericanos necesitan proteger" (74). ${ }^{6}$

Vemos que los roles se invierten acá. En vez de aceptar como cierta la perspectiva de la psicóloga estadounidense quien pone en tela de juicio las ideas persecutorias de su paciente, los lectores interpretaríamos los hechos en clave de conspiración y espionaje -una interpretación que, de hecho, se acerca a las ideas del personaje paranoico en "Ningún lugar sagrado". 7 Rivers se presentaría como un personaje poco fidedigno, siendo posiblemente una informante de los servicios de inteligencia estadounidenses. De acuerdo con este argumento, la psicóloga (o espía) conscientemente pone en cuestión las ideas persecutorias del narrador quien, en realidad, no exagera ni tergiversa los hechos.

En este contexto, me parece relevante retomar las observaciones de José Luis de Diego quien, como vimos en la introducción, despatologiza al personaje paranoico en situaciones de violencia política. Mientras que en una sociedad "sana", dice De Diego, el "sujeto paranoico" sería un "individuo psicótico" que se vuelve contra ella, en un "estado paranoico" que no admite voces disidentes, este encarnaría "un resto, una marginalidad lúcida, una ética no contaminada, una verdad inconmovible" (2014: 10, cursivas en el original). Compartiendo esta visión, creo que las ideas del personaje paranoico que introduce el cuento de Rey Rosa ponen de relieve una "marginalidad lúcida" que apunta al silencio cómplice de los Estados Unidos en el caso Gerardi. ${ }^{8}$

\footnotetext{
${ }^{6}$ La Misión de Verificación de las Naciones Unidas en Guatemala (Minugua) fue creada en 1997 con el fin de supervisar el cumplimiento Acuerdo sobre el Definitivo Cese al Fuego, firmado en 1996.

${ }^{7}$ A estas alturas, uno se podría preguntar si la lectura de "Ningún lugar sagrado" que propongo en este artículo es producto de lo que Ricardo Piglia ha llamado una "conciencia paranoica" ("La ficción paranoica"). En relación con esto, me parecen interesantes las observaciones de Kristine Vanden Berghe quien se pregunta si los "detectantes alternativos" que ella saca a la luz en su análisis de Rosario Tijeras (1999) de Jorge Franco "son meramente el producto de una mente lectora detectivesca" (2019: 100). Según Vanden Berghe, la novela del autor colombiano "no permite contestar a la pregunta de una manera unívoca" (100), sugiriendo también que este tipo de relatos policiales o de enigma requieren a un "lector incrédulo que lee con una desconfianza particular" (74). Creo que la ambigüedad que es característica de "Ningún lugar sagrado" y otras narrativas de Rey Rosa invita a una lectura similar, basada en una "desconfianza particular" que linda con la paranoia.

${ }^{8}$ En ¿Quién mató al obispo? Autopsia de un crimen político (2003), Maite Rico y Bertrand de la Grange presentan una reconstrucción detallada del caso Gerardi -crimen que fue acachado, injustamente según ellos, a tres militares: Byron Lima Estrada y su hijo Byron Lima Oliva, así como José Obdulio Villanueva. Constatan que los "indicios recopilados apuntan a que el magnicidio fue ideado por una estructura de la vieja inteligencia militar mafiosa, que reclutó a delincuentes y les dio apoyo logístico para montar una escena del crimen confusa y, por lo tanto, fácil de manipular a posteriori” (261, cursivas en el original), incluyendo "llamadas anónimas por una sobrina vengativa, documentos apócrifos y falsos testigos" (259). Según los autores, "lo más desolador es que los asesinos de Gerardi andan libres y que los cerebros de la conspiración retomaron sus posiciones de poder con el gobierno de [Alfonso] Portillo" (265). Destacan también el silencio cómplice de los Estados Unidos, al decir que "no es creíble que Estados Unidos no tenga toda la información sobre el caso, y a pesar de eso, su embajador protestó cuando la sala de apelaciones anuló el primer fallo y ordenó un nuevo juicio" (266): "Es una manera muy cómoda de lavar su imagen y hacer olvidar que durante la guerra fueron los mejores aliados del ejército. Ahora se presentan como abanderados de los derechos humanos" (266). En The Art of Political Murder (2007), Francisco Goldman toma una posición crítica con respecto a la tesis conspirativa de Maite Rico y Bertrand de la Grange: "A conspiracy of breathtaking scope was alleged, involving an enormous number of people and without any institutional oversight, any chain of command, or any central authority to
} 
De acuerdo con mi lectura de "Ningún lugar sagrado", la pregunta sobre la que nos invita a reflexionar el cuento de Rey Rosa no se dirige tanto al estatuto (verídico o delirante) de las ideas persecutorias del narrador, sino al contexto sociopolítico de represión donde tales ideas cobran fuerza. Efectivamente, el relato del personaje paranoico presenta un contrapunto con respecto a la perspectiva psicoanalítica de Rivers quien, como vimos, individualiza y despolitiza los recuerdos traumáticos de su paciente. Las ideas en clave de desaparición y persecución políticas que arma el narrador a lo largo de la historia van en contra de esta perspectiva, en el sentido de que redirigen la atención hacia la raíz sociopolítica de sus experiencias traumáticas. De hecho, la tendencia a la politización podría calificarse como un rasgo común en los relatos ficcionales de personajes paranoicos que tienden a prestar atención especial (a veces excesiva) a motivos políticos relacionados con la conspiración y la persecución. En "Ningún lugar sagrado", el enfoque psicoanalítico de Rivers que supone una interpretación despolitizada del trauma termina siendo sustituido por un enfoque 'paranoico' que permite repolitizar la narrativa del trauma.

Open Access This article is licensed under a Creative Commons Attribution 4.0 International License, which permits use, sharing, adaptation, distribution and reproduction in any medium or format, as long as you give appropriate credit to the original author(s) and the source, provide a link to the Creative Commons licence, and indicate if changes were made. The images or other third party material in this article are included in the article's Creative Commons licence, unless indicated otherwise in a credit line to the material. If material is not included in the article's Creative Commons licence and your intended use is not permitted by statutory regulation or exceeds the permitted use, you will need to obtain permission directly from the copyright holder. To view a copy of this licence, visit http://creativecommons.org/licen ses/by/4.0/.

\section{Obras citadas}

American Psychiatric Association. (2013). Diagnostic and statistical manual of mental disorders: DSM-5. Washington, D.C.: American Psychiatric Association.

Bernaerts, L. (2011). De retoriek van waanzin. Taalhandelingen, onbetrouwbaarheid, delirium en de waanzinnige ik-verteller. Antwerpen: Garant.

Bogle, L. L. (2001). The Cold War: Cold War espionage and spying. London: Taylor \& Francis.

Brooks, P. (2000). Troubling confessions. Speaking guilt in law and literature. Chicago: University of Chicago Press.

Cortez, B. (2010). Estética del cinismo. Pasión y el desencanto en la literatura centroamericana de posguerra. Ciudad de Guatemala: F\&G Editores.

Craps, S. (2013). Postcolonial witnessing. Trauma out of bounds. London: Palgrave Macmillan.

De Diego, J. L. (2014). La narrativa de Piglia: figuras retóricas y cuestiones de género. Anclajes, 18, $1-12$.

Footnote 8 (continued)

enforce their obedience and guard their silence" (267). De hecho, las ideas de conspiración de los autores de ¿Quién mató al obispo? recuerdan las reflexiones de Ricardo Piglia sobre la ficción paranoica: "Todos son sospechosos, todos se sienten perseguidos. El criminal ya no es un individuo, sino una gavilla que tiene el poder absoluto. Nadie comprende lo que está pasando; las pistas y los testimonios son contradictorios y mantienen las sospechas en el aire, como si cambiaran con cada interpretación" (2010: 284). El cuento de Rodrigo Rey Rosa parece adelantarse al ambiente confuso de intrigas, mentiras, complicidades y teorías conspirativas que surgió a partir del asesinato del obispo guatemalteco. 
Frederick, S. (2012). Narratives unsettled digression in Robert Walser, Thomas Bernhard, and Adalbert Stifter. Evanston, IL: Northwestern University Press.

Freeman, D., \& Freeman, J. (2009). Is paranoia increasing? The Psychologist, 22, 582-585.

Goldman, F. (2007). The art of political murder. Who killed the bishop?. New York: Grove Press.

Halfon, E. (2015). Better not say too much. The Guardian, 4 de noviembre de 2015.

Martín-Baró, I. (1990). Guerra y salud mental. In I. Martín-Baró (Ed.), Psicología social de la guerra: trauma y terapia (pp. 24-36). San Salvador: UCA Editores.

Oliver, M. P. (2016). El arte de irse por las ramas. La digresión en la novela latinoamericana contemporánea. Leiden: Brill Rodopi.

Piglia, R. (1991). La ficción paranoica. Clarín, 10 de octubre de 1991.

Piglia, R. (2010). Blanco nocturno. Barcelona: Anagrama.

Rey Rosa, R. (1998). Ningún lugar sagrado. Barcelona: Seix Barral.

Rico, M., \& De la Grange, B. (2003). Quién mató al obispo? Autopsia de un crimen político. México, D.F.: Editorial Planeta.

Vanden Berghe, K. (2019). Narcos y sicarios en la ciudad letrada. Valencia: Albatros.

Wallace, A. (2018). Horacio Castellanos Moya, escritor salvadoreño: "Los centroamericanos no son Estados fallidos, son Estados tullidos". BBC Mundo, 22 de mayo de 2018.

Publisher's Note Springer Nature remains neutral with regard to jurisdictional claims in published maps and institutional affiliations. 